\title{
PRODUÇÃO DO Pinus taeda L. EM POVOAMENTO DESBASTADO NA REGIÃO DOS CAMPOS DE CIMA DA SERRA, RIO GRANDE DO SUL.
}

\author{
YIELD OF Pinus taeda L. IN THINNED STAND IN THE CAMPOS \\ DE CIMA DA SERRA REGION, RIO GRANDE DO SUL.
}

\author{
Luiz Ernesto Grillo Elesbão ${ }^{1}$ Paulo Renato Schneider ${ }^{2}$
}

\begin{abstract}
RESUMO
Este trabalho foi realizado com o objetivo de estudar a produção do Pinus taeda L., implantado num espaçamento inicial de $3 \times 2 \mathrm{~m}$, localizado em Canela, estado do Rio Grande do Sul. A população amostral foi submetida a um e dois desbastes seletivos, além da manutenção de uma testemunha, sem desbaste. Os desbastes foram realizados por baixo com redução da área basal para níveis de $28 \mathrm{~m}^{2} \mathrm{ha}^{-1}$. Aos 17 anos, a produção total das parcelas testemunhas, sem desbaste, foi de $886,3 \mathrm{~m}^{3} \mathrm{ha}^{-1}$; com a realização de um desbaste aos 11 anos, de 756,6 $\mathrm{m}^{3} \mathrm{ha}^{-1}$, tendo resultado perdas de produção em relação a testemunha de 14,6 \%; com dois desbastes aos 11 e 15 anos, a produção foi de $732,9 \mathrm{~m}^{3} \mathrm{ha}^{-1}$, tendo provocado perdas de produção em relação à testemunha, sem desbaste, de $17,3 \%$. Os desbastes executados permitiram um ganho significativo em diâmetro, até os 17 anos de idade, com a execução de um desbaste aos 11 anos obteve-se um diâmetro médio de 33,4 cm; com dois desbastes aos 11 e 15 anos, um diâmetro médio de $33,5 \mathrm{~cm}$; e, um diâmetro médio de $24,3 \mathrm{~cm}$ na testemunha, sem desbaste.
\end{abstract}

Palavras-chave: produção; desbaste seletivo; área basal.

\begin{abstract}
This work was carried out with the objective of studying the yield of Pinus taeda L., planted in an initial spacing of $3 \times 2 \mathrm{~m}$, located in Canela, Rio Grande do Sul state. The amostral population was submitted to one and two selective thinning, beyond a control sample, without thinning. The selective low thinning was conducted with reduction of the basal area to levels of $28 \mathrm{~m}^{2} / \mathrm{ha}$. At age 17, the total yield of the control sample, without thinning, was $886.3 \mathrm{~m}^{3} \mathrm{ha}^{-1}$; with one thinning at age 11 the yield was $756.6 \mathrm{~m}^{3} \mathrm{ha}^{-}$ ${ }^{1}$, resulting in losses of yield of $14.6 \%$ compared to the control; with two selective at ages 11 and 15, the yield was $732.9 \mathrm{~m}^{3} \mathrm{ha}^{-1}$, resulting in losses of yield in relation with the control sample, without thinning, of $17.3 \%$. The selective thinning allowed a significant gain in diameter, up to age 17; with the execution of a selective thinning at age 11 an average diameter of $33.4 \mathrm{~cm}$; was obtained with two selective thinning at ages 11 and 15 an average diameter of $33.5 \mathrm{~cm}$; and an average diameter of $24.3 \mathrm{~cm}$ in the control sample, without thinning.
\end{abstract}

Keywords: yield; selective thinning; basal area.

\section{INTRODUÇÃO}

Entre os fatores que influem na produção qualitativa e quantitativa de madeira dos povoamentos florestais estão, em sua maioria, aqueles relacionados ao sítio, tratos silviculturais e, principalmente, à densidade da população. Assim, deve-se considerar que, à medida que existe um maior número de árvores na população, aumenta a área basal, até o momento em que inicia a competição entre as árvores, quando se estabelece o início da mortalidade natural na floresta e, com isso, a manutenção ou até mesmo a redução da área basal.

1. Engenheiro Florestal, M.Sc., Professor do Departamento de Ciências Florestais, Centro de Ciências Rurais, Universidade Federal de Santa Maria, Av. Roraima, 1000, CEP 97105-900, Santa Maria (RS).

2. Engenheiro Florestal, Dr., Professor do Departamento de Ciências Florestais, Centro de Ciências Rurais, Universidade Federal de Santa Maria, Av. Roraima, 1000, CEP 97105-900, Santa Maria (RS). paulors@smail.ufsm.br

Recebido para publicação em 15/10/2008 e aceito em 26/07/2010

Ci. Fl., v. 21, n. 1, jan.-mar., 2011 
As razões pelas quais ocorre redução da área basal total, em parte, podem ser atribuídas à redução da produção fotossintética, devido à diminuição da área de copa, e à limitação de disponibilidade de água e nutrientes absorvidos por cada indivíduo, como também à falta de desenvolvimento do sistema radicular. Então, através dos desbastes, é possível aumentar o espaço vital disponível, proporcionando o desenvolvimento equilibrado da copa e do sistema radicular, necessário para cada estado de dimensão da árvore.

A densidade do povoamento é o segundo fator em importância, depois da capacidade produtiva do sítio, para a determinação da produtividade de um local, sendo, no entanto, o principal fator que o silvicultor pode manejar durante o desenvolvimento de um povoamento (SCHNEIDER e SCHNEIDER, 2008).

Crechi et al. (2002) analisaram um experimento de desbaste em Pinus taeda, instalado em blocos completos ao acaso com 2 níveis de intensidade e testemunhas, 3 níveis de oportunidades e 3 repetições. Os tratamentos de intensidade foram definidos por área basal e caracterizados em: sem desbaste (testemunha) e desbaste de 33 e $66 \%$ da área basal da testemunha. Os 3 tratamentos de oportunidade foram definidos com periodicidade de 2, 4 e 6 anos. Foram observadas diferenças significativas entre os tratamentos para as produções totais por hectare aos 13 anos. As tendências no crescimento em diâmetro, área basal e volume total e parcial (30 $\mathrm{cm}$ na ponta fina) por hectare, para diferentes intensidades e oportunidades de desbaste avaliadas, demonstram que, para atender a objetivos de produção diferentes, deve-se variar a intensidade de desbaste, uma vez que este influi sobre a produção total.

No estudo desenvolvido por Pienaar apud Schneider (1993), foi demonstrado ser a assíntota do crescimento em área basal uma constante para uma larga faixa de altas densidades. Entretanto, segundo Reinstorf (1970), outros experimentos não forneceram essa clara indicação de resultados obtidos. Como exemplo, cita uma pesquisa que apresentou um crescimento em área basal, para povoamento com 3.000 árvores/ha, $14 \%$, superior ao de um povoamento com 1.000 árvores/ha, não havendo evidência de que as curvas tendessem para o mesmo valor de assíntota. E, com base em experimentos de desbaste em Pinus, concluiu o autor que o incremento em área basal relacionase estreitamente com a densidade, sendo maior nos povoamentos com alta densidade, e que a idade do ponto de máximo incremento em área basal aumenta com a diminuição da densidade. Também, observou que o diâmetro médio no momento do culmíneo do incremento em área basal era inversamente proporcional à densidade, ou seja, quanto maior a densidade, menor o diâmetro médio.

A decisão da realização ou não de um desbaste deve ser tomada com base técnica e econômica. Com base técnica, o estudo periódico da área basal pode servir como um indicador para decisão de desbaste como determinante do grau de estoqueamento, o qual é dado pela divisão da área basal real do povoamento por hectare, pela área basal de algum povoamento utilizado como base de comparação ou, mais freqüentemente, pela área basal de uma tabela de produção para um determinado sítio, permitindo conhecer a discrepância entre a área basal real e a tabelar e, por conseqüência, adequar o peso do desbaste à situação de campo (ASSMANN, 1970).

Com a aplicação de desbastes pesados, normalmente, abrem-se grandes espaços, propiciando um crescimento diamétrico superior a desbastes mais leves (REINSTORF, 1970). Nesse caso, acredita-se que o volume das árvores retiradas possa ser recuperado pelo crescimento do povoamento. Mas, existem limites para esse aumento em incremento, pois aberturas excessivas, graus muito fortes de desbaste, podem ocasionar perdas, resultando na queda da produção, pois as árvores remanescentes não são capazes de repor o volume retirado no desbaste (ALVES, 1982).

As áreas manejadas com desbastes pesados produzem menor volume total do que as com desbastes leves (ASSMANN, 1970). No mesmo sentido, Reinstorf (1970), estudando a influência da densidade populacional no crescimento de Pinus elliottii, constatou que a produção foi maior em povoamentos de alta densidade, quando comparada a povoamentos de menor densidade, e que a qualidade do sítio também influencia a produção.

Schneider e Finger (1991) estudaram a influência da intensidade de desbaste sobre o desenvolvimento da altura média e dominante de povoamentos de Pinus elliottii, submetidos a 4 (quatro) tratamentos de desbaste de 25,50 e $75 \%$ da área basal da testemunha sem desbaste, além da testemunha sem desbaste. Os resultados obtidos

Ci. Fl., v. 21, n. 1, jan.-mar., 2011 
permitiram concluir que a intensidade do desbaste influi no desenvolvimento da altura média, mas não no da altura dominante.

Com base no incremento das árvores remanescentes após o desbaste, Assmann (1968) definiu três valores característicos de área basal, ou seja: a área basal máxima, que ocorre quando o povoamento obtém a maior área basal para o sítio sobre um período com lotação total por hectare, podendo ser determinada para povoamentos não desbastados; a área basal ótima sobre um período, em que o mais alto valor de incremento volumétrico pode ser alcançado em um período de crescimento; a área basal crítica sobre um período, no qual se atingiu cerca de $95 \%$ do incremento máximo potencial, ou seja, $5 \%$ a menos que o obtido na área basal ótima de um sítio.

Glufke (1996) estudou as perdas de incremento de Pinus elliottii, submetido a desbaste com controle da área basal. Os resultados obtidos demonstram que, com uma prática correta de desbaste, é possível obter incrementos muito próximos do máximo. Com a retirada de $10 \% \mathrm{em}$ relação à área basal máxima da testemunha, obtémse uma perda de $2 \%$ no incremento; retirandose $70 \%$, a perda é de $39 \%$; e com a retirada de $80 \%$ em relação a área basal máxima, a perda é de $82 \%$.

O objetivo específico é estudar a existência de diferença de produção de povoamentos manejados com um e dois desbastes seletivos por baixo, com controle da área basal, e em densidade completa, sem desbaste.

\section{MATERIAL E MÉTODOS}

O estudo foi realizado na Agropecuária Fazenda do Ipê Ltda, localizada no município de Canela, no estado do Rio Grande do Sul. A área situa-se entre as coordenadas $29^{\circ} 17^{\prime} 41.28^{\prime \prime}$ de latitude Sul e $50^{\circ} 46^{\prime} 01.00^{\prime}$ "de longitude Oeste, numa altitude de 820 metros.

O clima dominante da região dos Campos de Cima da Serra, correspondente à área deste estudo, segundo o sistema de classificação de Köppen, é do tipo "Cfb1", temperado úmido (MORENO, 1961).

De acordo com IPAGRO (1989), a região do município de Canela, estado do Rio Grande do Sul, possui as seguintes médias anuais: temperatura mínima média de $10^{\circ} \mathrm{C}$; temperatura máxima média de $21,3^{\circ} \mathrm{C}$; temperatura média anual de $14,8^{\circ} \mathrm{C}$; precipitação média anual de $1821 \mathrm{~mm}$; umidade relativa do ar média de $80 \%$.

Segundo Lemos et al. (1973), a região enquadra-se no grupo São Bento, o qual abrange as formações da Serra Geral, Botucatu e Rosário do Sul. Especificamente, o local em estudo encontra-se na formação Serra Geral, caracterizada por derrames de lava basáltica.

O povoamento florestal estudado é constituído de Pinus taeda, implantado em 1987, num espaçamento inicial de $3 \times 2$ metros, com o objetivo de produção de madeira de grandes dimensões, com um maior valor agregado.

Para alcançar os objetivos propostos, foram formuladas situações experimentais em população submetida a desbaste por baixo: execução de um desbaste, quando a área basal atingir cerca de 45 $\mathrm{m}^{2} \mathrm{ha}^{-1}$, com redução da área basal para níveis de $28 \mathrm{~m}^{2} \mathrm{ha}^{-1}$; execução de dois desbastes, o primeiro quando a área basal atingir cerca de $45 \mathrm{~m}^{2} \mathrm{ha}^{-1}$, com redução da área basal para níveis de $28 \mathrm{~m}^{2} \mathrm{ha}^{-1}$, o segundo, aos 15 anos, com redução da área basal para o mesmo nível de $28 \mathrm{~m}^{2} \mathrm{ha}^{-1}$; outro tratamento sem desbaste, testemunha.

As parcelas tiveram uma superfície útil de $600 \mathrm{~m}^{2}$, com um tamanho de $30 \times 20 \mathrm{~m}$, com uma bordadura de uma fila de árvores. O controle do crescimento e produção, nessas populações experimentais, foi realizado com base em 8 parcelas permanentes. Essas parcelas sofreram aplicação de um desbaste por baixo e redução da área basal para um nível de $28 \mathrm{~m}^{2} / \mathrm{ha}$, mais 8 parcelas permanentes, com aplicação de dois desbastes por baixo e redução da área basal para um nível de $28 \mathrm{~m}^{2} \mathrm{ha}^{-1}$, bem como mantiveram-se três parcelas-testemunha, sem desbaste.

Para a análise de tronco, foram abatidas 8 árvores, sendo 4 árvores dominantes e 4 de diâmetro médio, distribuídas nos tratamentos. As árvores abatidas foram seccionadas em toras no comprimento padrão de $2,2 \mathrm{~m}$.

A identificação dos anéis de crescimento foi realizada de acordo com a orientação de Schweingruber (1996), que descreveu os problemas na identificação de anéis de crescimento anual em Pinus. As medições dos anéis de crescimento foram realizadas no aparelho Lintab II e, posteriormente, esses dados medidos foram processados no programa ANATRO (Análise de Tronco).

As análises estatísticas e regressões foram determinadas pelo procedimento de regressão, no pacote SAS - Statistical Analysis System (2004). 


\section{RESULTADOS E DISCUSSÃO}

Na Tabela 1, são apresentados os resultados da produção da população experimental, submetida a um desbaste, dois desbastes e testemunha sem desbaste, cujas variáveis encontram-se discriminadas para o povoamento atual, desbaste e produção total, aos 17 anos de idade.

Na Figura 1, é apresentada a produção total da testemunha, da população manejada com um desbaste, com redução da área basal para níveis de $28 \mathrm{~m}^{2} / \mathrm{ha}$, e com dois desbastes, com redução da área basal para níveis de $28 \mathrm{~m}^{2} / \mathrm{ha}$, no primeiro e segundo desbastes.

A produção total das parcelas-testemunha, sem desbaste, foi de $886,3 \mathrm{~m}^{3} /$ ha, superior à obtida com a realização de um desbaste, aos 11 anos, de $756,6 \mathrm{~m}^{3} / \mathrm{ha}$ e, com dois desbastes, aos 11 e 15 anos, de $732,9 \mathrm{~m}^{3} / \mathrm{ha}$, em relação à testemunha, sem desbaste.

Em termos relativos, até os 17 anos de idade, a população manejada com a execução de um desbaste resultou em uma redução de produção de $14,6 \%$, e a com dois desbastes, em uma redução de $17,3 \%$, ambas em relação à testemunha, sem desbaste. Essas perdas de produção, por realização de desbaste, são previsíveis no curto prazo, no caso 17 anos de idade, pela execução dos desbastes pesados, pois, ainda, não havia tempo suficiente para os povoamentos poderem incorporar área basal e a massa desbastada.

Os resultados obtidos com a aplicação de um e dois desbastes não permitem confirmar a Teoria de Mar:Müller de que "dentro de certos limites de densidade, o incremento em volume não é afetado pelos desbastes", pelo fato de os desbastes terem sido executados pesadamente e de os povoamentos não terem ainda atingido a idade de rotação. Por outro lado, coincide com os resultados obtidos por Glufke (1996), para Pinus elliottii, de que se retirando $70 \%$ da área basal, em relação a uma testemunha sem desbaste, pode-se provocar perdas de $39 \%$ de produção.

Porém, os desbastes executados, quando comparados à testemunha, sem desbaste, provocaram um ganho significativo em diâmetro, até os 17 anos de idade, pois, com a realização de um desbaste aos 11 anos, obteve-se um diâmetro médio de $33,4 \mathrm{~cm}$ e, com dois desbastes, aos 11 e 15 anos, de $33,5 \mathrm{~cm}$, contra os $24,3 \mathrm{~cm}$ na testemunha, sem desbaste. Isso equivale a ganhos significativos em diâmetro de $9,1 \mathrm{~cm}$, ou seja, 37,4 \%, com a execução de um desbaste, e $9,2 \mathrm{~cm}$, ou seja, $37,9 \%$, quando aplicados dois desbastes. Esses incrementos significativos são resultado da execução dos desbastes, mas que, inversamente, produzem uma redução na produção volumétrica, que deve ser compensada

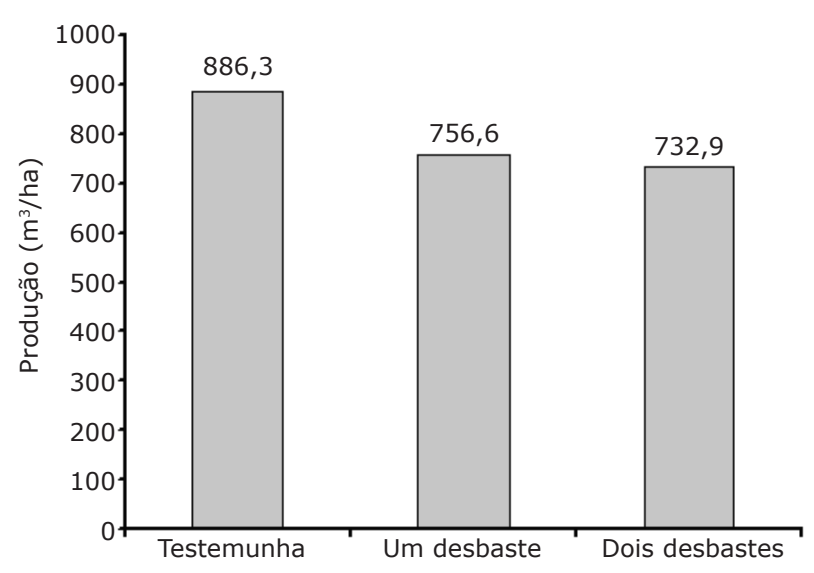

FIGURA 1: Produção das populações submetidas a um e dois desbastes e testemunha, aos 17 anos de idade.

FIGURE 1: Yield of the stands submitted to one and two thinnings, at 17 years of age.

TABELA 1: Parâmetros das parcelas submetidas a um e dois desbastes, com controle da área basal remanescente, e testemunha, aos 17 anos de idade.

TABLE 1: Parameters of the stands submitted to one and two thinnings with control of the remaining basal area, and control sample, at 17 years of age.

\begin{tabular}{c|c|c|c|c|c|c|c|c|c|c}
\hline \multirow{2}{*}{ Tratamento } & \multicolumn{4}{|c|}{ Povoamento Atual } & \multicolumn{2}{c|}{ Desbaste } & \multicolumn{2}{c}{ Produção } \\
\cline { 2 - 12 } & $\begin{array}{c}\mathrm{d} \\
\mathrm{cm}\end{array}$ & $\begin{array}{c}\mathrm{h} \\
\mathrm{m}\end{array}$ & $\begin{array}{c}\mathrm{h}_{100} \\
\mathrm{~m}\end{array}$ & $\begin{array}{c}\mathrm{G} \\
\mathrm{m}^{2} / \mathrm{ha}\end{array}$ & $\begin{array}{c}\mathrm{N} \\
\mathrm{ha}\end{array}$ & $\begin{array}{c}\mathrm{V} \\
\mathrm{m}^{3} / \mathrm{ha}\end{array}$ & $\begin{array}{c}\mathrm{V}^{1)} \\
\mathrm{m}^{3} / \mathrm{ha}\end{array}$ & $\begin{array}{c}\mathrm{V}^{2} \\
\mathrm{~m}^{3} / \mathrm{ha}\end{array}$ & $\begin{array}{c}\mathrm{V} \\
\mathrm{m}^{3} / \mathrm{ha}\end{array}$ & $\begin{array}{c}\mathrm{IMA} \\
\mathrm{m}^{3} \mathrm{~h} / \mathrm{ano}\end{array}$ \\
\hline 1 Desb. & 33,4 & 25,4 & 28,5 & 34,1 & 390 & 457,6 & 298,9 & & 756,6 & 44,5 \\
\hline 2 Desb. & 33,5 & 25,4 & 28,4 & 25,0 & 286 & 335,6 & 297,5 & 99,8 & 732,9 & 43,1 \\
\hline Test. & 24,3 & 24,0 & 28,3 & 69,7 & 1500 & 886,3 & - & - & 886,3 & 52,1 \\
\hline
\end{tabular}

Em que: $\mathrm{d}=$ diâmetro; $\mathrm{h}=$ altura média; $\mathrm{h}_{100}=$ altura dominante; $\mathrm{G}=$ área basal; $\mathrm{N}=$ número de árvores; $\mathrm{V}=$ volume com casca; IMA = incremento médio anual; Desb. $=$ Desbaste; Test. $=$ Testemunha $;{ }^{1)}=$ primeiro desbaste $;{ }^{2}{ }^{2}=$ segundo desbaste. 
pelo valor econômico agregado aos produtos com maior dimensão, obtidos com a aplicação dos desbastes.

No entanto, é importante ressaltar que não houve um ganho significativo de incremento diamétrico com a aplicação de dois desbastes em relação a um desbaste, até os 17 anos de idade, o que possivelmente deve perdurar até da idade de rotação. Então, pode-se presumir que, nessas circunstâncias, a decisão técnica de realizar um segundo desbaste, 4 anos após o primeiro, não produz efeitos positivos, nem em incremento diamétrico, nem em produção volumétrica.

Quanto ao crescimento em altura e altura dominante, não se pode atribuir influência ao peso e nem ao número de desbastes executados, pois os valores encontrados são numericamente semelhantes. Isso vem a confirmar a Teoria de Assmann, de que o peso do desbaste não produz efeito sobre o valor da altura dominante, porém pode afetar a altura média, como decorrência do tipo de desbaste executado. Esses resultados também confirmam os obtidos por Schneider e Finger (1993).

As frequências por classe de diâmetro da população experimental, com um e dois desbastes, encontram-se representadas na Figura 2. Observase que, tanto com a execução de um desbaste como com dois desbastes, as distribuições de

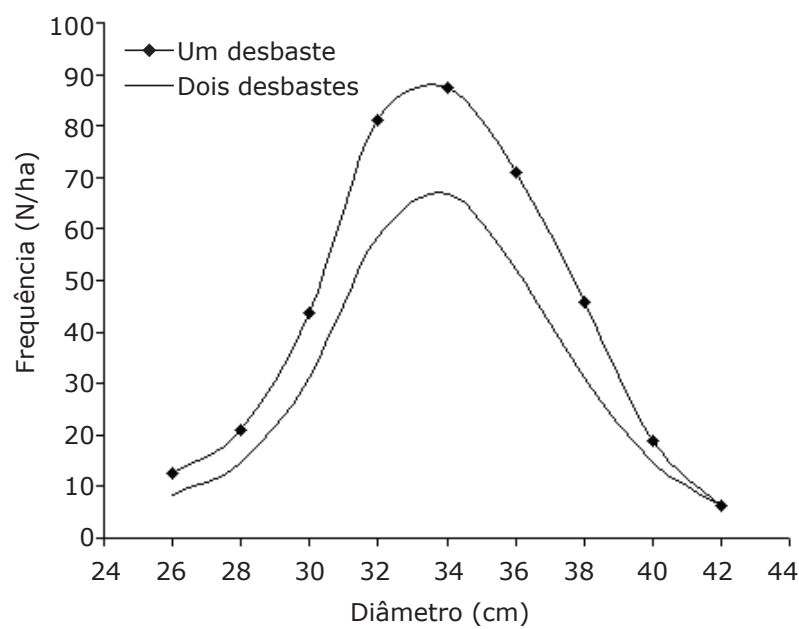

FIGURA 2: Distribuição de frequência por classe de diâmetro das populações submetidas a um e dois desbastes, aos 17 anos de idade.

FIGURE 2: Frequency distribution by diameter classes of the stand submitted to one and two thinnings, at 17 years of age. frequência por classe de diâmetro mantiveram-se, aproximadamente, normais, aos 17 anos de idade. Portanto, os desbastes não provocaram alterações na normalidade da distribuição de frequência por classe de diâmetro nas duas populações analisadas, Isso, provavelmente, é uma decorrência da própria execução dos desbastes por baixo, em ambos os casos.

Por outro lado, quantitativamente, as frequências por classe de diâmetro alteraram-se de forma significativa. Isso permitiu constatar que a realização do segundo desbaste, além de provocar perdas de produção volumétrica, não produziu um recrutamento de indivíduos para as maiores classes de diâmetro, o que seria esperado até a idade de 17 anos.

Nessas condições de manejo, com a realização de um desbaste aos 11 anos, quando a área basal atingiu $45 \mathrm{~m}^{2} \mathrm{ha}^{-1}$, obteve-se um total de 388 árvores por hectare, enquanto que, com a aplicação de dois desbastes aos 11 e 15 anos, obteve-se um total de 283 árvores por hectare, na idade de 17 anos. Isso equivale a uma diferença relativa de $26,9 \%$, que aliada às diferenças absolutas de frequência nas classes de diâmetro, traduz-se invariavelmente num reflexo negativo no fluxo de caixa de uma empresa, ocasionado pelo simples fato de uma decisão técnica equivocada de realização de desbastes.

Espera-se que, no final da rotação, a distribuição das frequências e volumes por classe diamétrica apresente uma maior diferenciação, talvez em favor do manejo com dois desbastes, em restrição ao com um desbaste. Porém, nessas condições de crescimento, até os 17 anos de idade, a melhor opção de manejo seria a aplicação de um único desbaste. Porém, reside ainda a dúvida sobre o peso e ciclo ideais para a espécie e sítios, o que se deveria pesquisar com maior profundidade, enfocando a maximização da produção, ganho diamétrico e, consequentemente, o recrutamento das frequências por classe de diâmetro.

\section{CONCLUSÕES}

A produção total das parcelas-testemunha, sem desbaste, foi de $886,3 \mathrm{~m}^{3} /$ há; com a realização de um desbaste, aos 11 anos, foi de $756,6 \mathrm{~m}^{3} / \mathrm{ha}$, resultando em perdas de $14,6 \%$ de produção; com dois desbastes, aos 11 e 15 anos, de 732,9 m²/ha, provocando perdas de $17,3 \%$ de produção, em relação à testemunha. 
Os desbastes executados provocaram um ganho significativo em diâmetro, até os 17 anos de idade: com a execução de um desbaste aos 11 anos, o diâmetro médio foi de $33,4 \mathrm{~cm}$ e, com dois desbastes, aos 11 e 15 anos, foi de $33,5 \mathrm{~cm}$, para um diâmetro médio de $24,3 \mathrm{~cm}$ na testemunha, sem desbaste.

Os desbastes aplicados provocaram alteração significativa nas frequências por classe de diâmetro. A execução do segundo desbaste, além de ter provocado perdas de produção volumétrica, não produziu ganho em incremento diamétrico $\mathrm{e}$ nem o recrutamento significativo de indivíduos para as maiores classes de diâmetro, até os 17 anos de idade.

\section{REFERÊNCIAS BIBLIOGRÁFICAS}

ALVES, M. A. A. Técnica de produção florestal: fundamentos, tipificação e métodos. Lisboa: Instituto Nacional de Investigação Científica, 1982. $331 \mathrm{p}$.

ASSMANN, E. The principle of forest yield study. Oxford: Pergamon press, $1970.506 \mathrm{p}$.

ASSMANN,E.ZurTheoriederGrundflächenhaltung, Fw. Gbl. v. 78. p. 321-330. 1968.

CRECHI, E. H. et al. Efectos de la Intensidad y Oportunidad de Raleo en Pinus taeda L. sobre el crecimiento y la producción en el noroeste de Misiones, Argentina. In: SIMPÓSIO LATINOAMERICANO SOBRE MANEJO FLORESTAL, 2., 2002, Santa Maria. Anais... Santa Maria, 2002. p. $189-210$.

GLUFKE, C. Crescimento de Pinus elliottii Engelm. em povoamento desbastado. $1996.73 \mathrm{f}$. Dissertação (Mestrado em Engenharia Florestal)Universidade Federal de Santa Maria, Santa Maria,
1996.

IPAGRO. Instituto de Pesquisas Agronômicas. Seção de Ecologia Agrícola. Atlas-agroclimático do Estado do Rio Grande do Sul. Porto Alegre: IPAGRO, 1989. $3 \mathrm{v}$.

LEMOS, R. C. et al. Levantamento de reconhecimento dos solos do Estado do Rio Grande do Sul. Recife: Ministério da Agricultura, Departamento de Pesquisas Agropecuárias, Divisão de Pesquisas Pedológicas, 1973. 431 p. (Boletim Técnico, 30).

MORENO, J. A. Clima do Rio Grande do Sul. Porto Alegre: Oficinas Gráficas da Secretaria da Agricultura, 1961. $41 \mathrm{p}$.

REINSTORF, L. O. The influence of stand density on growth of Pinus elliottii. Stellenbosch: Forestry University of Stellenbosch, 1970. 62 f. Dissertação (Mestrado) - University of Stellenbosch, 1970.

SAS. A simple regression model with correction of heteroscedasticity. Cary: SAS Institute, 2004.

SCHNEIDER, P. R. et al. Efeito da intensidade de desbaste sobre o crescimento e produção de povoamentos de Pinus elliottii Engelm. In: SIMPÓSIO DE MANEJO DE FLORESTAS PLANTADAS, 1991, Santa Maria. Anais... Esteio: UFSM, 1991. p.150-167.

SCHNEIDER, P. R.; SCHNEIDER, P. S. P. Introdução ao Manejo florestal. Santa Maria: Ed. FACOS, 2008. 566 p.

SCHNEIDER. P. R.; FINGER, C. A. G. Influência da intensidade do desbaste sobre o crescimento em altura de Pinus elliottii Engelm. Ciência Florestal, Santa Maria, v. 3, n. 1, p. 95103. 1993b.

SCHWEINBRUGER, F. H. Tree rings and environment dendroecology. Viena: Haupt. 1996. $609 \mathrm{p}$. 